\title{
TRÂNSITO URBANO: O LIMIAR DO CAOS? POLÍTICAS DE GESTÃO E MOBILIDADE URBANA
}

\author{
Juliana Flávia Mattei ${ }^{1}$ \\ Laura Lúcia da Silva Amorim² \\ Mônica Souza Liedke ${ }^{3}$
}

\section{RESUMO}

A frota de veículos que se verifica cada dia maior em nosso cotidiano traz à tona a discussão acerca dos problemas ambientais que os meios de transporte provocam no ambiente, assim como nos conduz a uma reflexão sobre a mobilidade urbana. As estradas e rodovias não comportam mais o imenso número de carros, caminhões, motos, etc. A fabricação de combustíveis menos poluentes, de veículos movidos a energia elétrica, de utilização de resíduos alimentares para confecção e alimentação dos veículos, entre outros, são alternativas que se apresentam a fim de coibir a poluição ambiental. Há necessidade da criação de uma política nacional urbana que contemple a mobilidade. As políticas públicas possuem papel importante na promoção de campanhas que visem a educação ambiental da população, bem como, que incentivem a utilização de transportes coletivos ou alternativos, tais como bicicleta, patins ou caminhadas.

PALAVRAS-CHAVE: mobilidade urbana - meio ambiente - meios de transporte - políticas públicas

\section{SUMMARY}

The fleet of vehicles where there is increasing in our daily life brings up the discussion about environmental problems that the means of transport cause to the environment, and leads us to reflect on urban mobility. Roads and highways no longer support the huge number of cars, trucks, motorcycles, etc. The production of cleaner fuels, vehicles powered by

\footnotetext{
${ }^{1}$ Mestre em Direito na Universidade de Caxias do Sul (UCS) Mestre em Direito na Universidade de Caxias do Sul (UCS) Advogada-Sócia do FRANCO | Advogados, Brasil, Homepage: www.francoadv.com

${ }^{2}$ Mestrado em Direito Ambiental e sociedade pela Universidade de Caxias do Sul, Brasil(2009) . Professor Adjunto N2 da Associação de Ensino e Cultura Pio Décimo S/C Ltda, Brasil. Doutoranda em Ciências Jurídicas y Sociales na Universidad del Museo Social Argentino - UMSA- Buenos Aires /AR. Presta consultoria em Gestão de Projetos Ambientais e Arbitragem Ad hoc é docente da Faculdade Pio Décimo em Aracaju/SE

${ }^{3}$ Mestrado em Direito pela Universidade de Caxias do Sul, Brasil(2009) . Tem experiência na área de Direito, com ênfase em Bioética e Biodireito, Direito Ambiental, Direitos Fundamentais, Direitos Sexuais e Reprodutivos e Gênero
} 
electricity, the use of food waste to manufacture and supply of vehicles, among others, are alternatives that are presented in order to curb environmental pollution. There is need to develop a national policy that addresses urban mobility. Public policies have an important role in promoting the campaigns to incentive environmental education, as well as encouraging the use of public transport or alternative, such as cycling, skating or hiking.

policy

KEYWORDS: urban mobility - the environment - means of transport - public

\section{Introdução}

Ao longo dos últimos anos, o setor dos transportes evoluiu bastante no Brasil. É claro que existem muitas deficiências e algumas medidas a serem repensadas para evitar problemas de mobilidade urbana e ambientais. Os transportes coletivos que deveriam ser os mais utilizados pela população deixam a desejar, o que acaba por incentivar o transporte individual agravando os deslocamentos diários, assim como todos os tipos de poluição.

A mobilidade urbana envolve todos os tipos de deslocamentos ocorridos entre o lugar de saída e o de chegada. A mobilidade envolve o ser humano, os veículos, as vias e o ambiente. Todos esses elementos atuam de forma articulada no que se refere aos deslocamentos, interferindo de forma ativa, melhora ou piora da mobilidade urbana. O uso de combustíveis que provocam poluição atmosférica, as placas instaladas ao longo das rodovias, a falta de calçadas e rampas de acesso aos portadores de necessidades especiais, a falta de estacionamentos, as poucas ciclovias, a ineficiência dos transportes coletivos são alguns exemplos que provocam o caos nas cidades contribuindo de forma negativa para a mobilidade urbana sustentável.

Além destes fatos, outro muito grave e que muitas vezes não se relaciona de imediato com mobilidade urbana, mas que afeta diretamente a vida e a mobilidade nas cidades é a expansão imobiliária não programada. As grandes construções residenciais, edifícios e condomínios, em bairros sem infra-estrutura, afeta diretamente a mobilidade urbana.

O crescimento dos bairros de forma não planejada e o a maior concentração de pessoas nas áreas periféricas igualmente podem ser apontadas como causa de congestionamentos que 
passam pelas vias principais e secundárias das cidades, já que tal crescimento em regra não vem acompanhado da expansão das vias que seria necessária.

O Brasil tem se preocupado com as questões relativas à mobilidade urbana e o meio ambiente. Prova disso é criação do Ministério das Cidades e a instituição da SEMOB Secretaria Nacional de Transporte e Mobilidade Urbana a fim de elaborar práticas preventivas e repressivas que promovam o desenvolvimento sustentável, ao mesmo tempo em que preservem o ambiente, incluindo a agenciamento da qualidade de vida dos indivíduos. Muito já foi feito, pensado e implementado através de políticas públicas que informam e educam a população, mas, ainda deverão ser incentivadas outras alternativas que auxiliem a melhorar a mobilidade urbana, o que se propõe analisar no presente estudo.

\section{O cenário atual brasileiro: os meios de transporte e caos}

O transporte brasileiro está concentrado em quatro principais espécies: rodoviário, ferroviário, hidroviário e marítimo. De acordo com o Plano Nacional de Logística e Transportes - PNLT, do Ministério dos Transportes, 58\% da população utiliza o transporte rodoviário, $25 \%$ o ferroviário, $13 \%$ o aquaviário e $4 \%$ o dutoviário e aero. ${ }^{4}$

No Brasil, há cerca de 1.355.000 quilômetros de rodovias. As estradas são as principais vias de transporte de carga e de passageiros. Além disso, há cerca de 2.498 aeroportos, incluídas as pistas de pouso, enquanto a malha ferroviária é pequena e o transporte marítimo/pluvial, por sua vez, localizado. ${ }^{5}$

A compreensão da exata situação atual do transporte urbano coletivo no Brasil requer o apanhado histórico de forma breve, apresentando apenas alguns marcos:

a) O primeiro serviço de ônibus efetivo no Rio de Janeiro surgiu em julho de 1838, com dois carros de dois pavimentos. ${ }^{6}$

\footnotetext{
${ }^{4}$ Plano Nacional de Logística e Transportes - PNLT, Ministério dos Transportes, Secretaria de Política Nacional de Transportes, 2009. Disponível: http://www.transportes.gov.br/Bit/pg-inicial.htm. Acesso em: 22/07/2009.

${ }^{5}$ Disponível em: http://pt.wikipedia.org/wiki/Transportes_do_Brasil. Acesso em: 24/05/2009.

${ }^{6}$ A Companhia de Ônibus, concessionária do serviço, foi criada por iniciativa de Aureliano de Sousa e Oliveira Coutinho, Paulo Barbosa da Silva, José Ribeiro da Silva, Manoel Odorico Mendes e Carlos Augusto Taunay. Este último foi constituído agente da companhia, e fez contato com capitalistas que se interessassem em investir. As linhas da companhia deveriam partir do Centro para Botafogo, Engenho Velho e São Cristóvão no princípio, para posteriormente se estenderem a outros locais. Após dificuldades iniciais, como a oposição dos proprietários
} 
b) Em 30 de janeiro de 1859, começava a circular experimentalmente o primeiro bonde do Brasil, por iniciativa de Thomas Cochrane, que, para tal, criou a "Companhia de Carris de Ferro da Cidade à Boa Vista". 7

c) O primeiro bonde elétrico do Brasil e de toda América do Sul foi o carro de $n^{\circ} 104$ da Cia. Ferro-Carril do Jardim Botânico, que teve sua apresentação e entrada em serviço em 8 de outubro de $1892 .^{8}$

d) No ano de 1908, foi introduzido o primeiro serviço regular de ônibus a gasolina do Brasil. $^{9}$

e) Em 1918, foi inaugurado o primeiro serviço de ônibus elétricos no Rio de Janeiro. ${ }^{10}$

Daquela época até os dias atuais, o transporte urbano passou por diversas alterações que agravaram o meio ambiente, as condições de locomoção de forma rápida, provocando enormes congestionamentos nas metrópoles e ao seu redor. O incentivo ao consumo, a redução do IPI - Imposto sobre Produtos Industrializados contribuiu de forma negativa para esse aumento dos veículos nas estradas. O alto custo dos transportes coletivos e suas péssimas condições também ajudaram no agravamento do aumento de veículos nas ruas, pois isso deu início ao transporte irregular. Nesse sentido,

as mudanças verificadas na dinâmica da ocupação urbana no Brasil, com maior
crescimento da periferia, que geraram uma demanda de rede de transporte distinta da
construída; o crescimento do transporte individual (tanto motorizado quanto a pé e
por bicicleta) e do transporte coletivo informal (por vans, peruas, mototáxis,
lotações); a sobrecarga do sistema viário das cidades, reduzindo a fluidez do tráfego

de carros de praça, a companhia prosperou bastante. Disponível em: http://www.museudantu.org.br/QBrasil.htm. Acesso em: 22/07/2009.

${ }^{7}$ A inauguração dos serviços regulares se deu em 26 de março de 1859, com a presença de do Imperador D.Pedro II e sua esposa. A força animal foi substituída em 1862 pelo vapor, mas a empresa, não conseguindo superar dificuldades financeiras, faliu em 1866. Disponível em: http://www.museudantu.org.br/QBrasil.htm. Acesso em: 22/07/2009.

${ }^{8} \mathrm{O}$ trem partiu do centro da cidade e terminou a viagem inaugural no escritório da companhia, no Largo do Machado, levando diversos convidados ilustres. Disponível em: http://www.museudantu.org.br/QBrasil.htm. Acesso em: 22/07/2009.

${ }^{9}$ Em comemoração aos 100 anos da abertura dos portos por D. João VI, foi realizada na Praia Vermelha a Exposição Nacional. O empresário Otávio da Rocha Miranda obteve então da prefeitura uma concessão para a implantação, em caráter provisório, de uma linha de auto-ônibus que circulava ao longo da avenida Central, hoje Rio Branco. Os veículos também realizavam viagens extraordinárias do centro da cidade até o local da Exposição, na Praia Vermelha. A mecânica desses carros era do fabricante Daimler, e a carroceria de origem francesa. Disponível em: http://www.museudantu.org.br/QBrasil.htm. Acesso em: 22/07/2009.

${ }^{10}$ Em 1917, a prefeitura aprova a instalação de um serviço de ônibus pela Av. Rio Branco, entre a praça Mauá e o Palácio do Monroe (antigo Senado). Foram utilizados carros elétricos movidos a bateria, construídos nos Estados Unidos. Tendo sido os veículos aprovados nos testes, o serviço foi inaugurado em 1918, durando até 1928. Disponível em: http://www.museudantu.org.br/QBrasil.htm. Acesso em: 22/07/2009. 
e diminuindo a velocidade, o conforto e a regularidade do transporte coletivo; e o elevado número de mortes por atropelamento, como conseqüência da disputa pelo uso do espaço urbano entre pedestres e automóveis. Contudo, pode-se alegar que foi a queda da demanda pelos serviços de ônibus urbanos no período após a estabilização da moeda. ${ }^{11}$

O reconhecimento do problema do transporte urbano pelo governo federal pós-1990, ano da extinção da Empresa Brasileira de Transportes Urbanos (EBTU), deu-se em 2000, quando da criação do Grupo Executivo de Transporte Urbano (GTrans) na antiga Secretaria Especial de Desenvolvimento Urbano da Presidência da República (Sedu/PR).

Em 2003, foi criado o Ministério das Cidades, o qual foi estruturado com a criação de quatro secretarias nacionais, envolvendo os principais setores relacionados ao desenvolvimento urbano: habitação, saneamento, programas urbanos e transportes urbanos. Foram transferidos ao Ministério das Cidades o Departamento Nacional de Trânsito (Denatran), que pertencia ao Ministério da Justiça, assim como a Companhia Brasileira de Trens Urbanos (CBTU) e a Empresa de Trens Urbanos de Porto Alegre (Trensurb), que estavam vinculadas ao Ministério dos Transportes.

A criação do Ministério das Cidades significou um novo contexto institucional para a questão dos transportes urbanos. As ações previstas para a área almejavam a sua integração com as demais políticas urbanas, especialmente de controle e uso do solo. Nesse sentido, a recém-criada Secretaria Nacional de Transporte e Mobilidade Urbana (SEMOB) ${ }^{12}$ se constituiu em um novo ponto de canalização das demandas do setor.

A Secretaria Nacional de Transporte e Mobilidade Urbana do Ministério das Cidades (SEMOB) apontou em seu diagnóstico acerca do problema: o crescimento urbano desordenado, com o conseqüente "espraiamento" das cidades, que provocou o encarecimento da oferta dos serviços de transporte e a segregação sócio-espacial dos mais pobres, sobretudo nas periferias; os custos sociais, ambientais e econômicos provocados pelo atual modelo de mobilidade urbana das cidades brasileiras (congestionamentos, poluição, acidentes, consumo

\footnotetext{
${ }^{11}$ Secretaria Especial de Desenvolvimento Urbano (SEDU).

${ }^{12}$ A Secretaria Nacional de Transporte e da Mobilidade Urbana - SEMOB possui três eixos estratégicos que agrupam as questões a serem enfrentadas.

1. Promover a cidadania e a inclusão social por meio da universalização do acesso aos serviços públicos de transporte coletivo e do aumento da mobilidade urbana;

2. Promover o aperfeiçoamento institucional, regulatório e da gestão no setor; e

3. Coordenar ações para a integração das políticas da mobilidade e destas com as demais políticas de desenvolvimento urbano e de proteção ao meio ambiente.
} 
ineficiente do espaço urbano e de energia não-renovável); a baixa capacidade de investimento público para fazer frente às necessidades de infra-estrutura de transportes nas grandes cidades (metrôs, corredores de ônibus etc.); as mudanças de hábitos e necessidades de deslocamentos da população, causadas pelo processo de reestruturação produtiva, pela ampliação do uso dos meios de transporte individual (autos e motos), e pelas novas tecnologias de comunicação; a baixa integração setorial, institucional e territorial das políticas urbanas, destacadamente nas regiões metropolitanas; a baixa capacidade de gestão do setor público; e a fragilidade e a inadequação da regulação dos serviços de transporte coletivo na maioria das cidades brasileiras. $^{13}$

O aparecimento das vans, que possibilitaram a informalidade nos serviços, e o barateamento relativo dos automóveis e motocicletas, que provocou o crescimento da motorização individual, promoveram mudanças significativas no mercado de transportes urbanos, com a queda da demanda pelos serviços de transporte coletivo. Além disso, as transformações sócio-espaciais e econômicas fizeram com que os fluxos de deslocamentos deixassem de ter horários e pontos específicos, dado que a rotina de trabalho é cada vez menos fixa. Com estas mudanças, os congestionamentos estão deixando de ter pontos e horários determinados, espalhando-se por todas as regiões das grandes cidades.

Outro fator que concorre ao aumento de movimento da população são as atuais isenções e descontos na tarifa do transporte coletivo para determinados segmentos (idosos, estudantes, pessoas com deficiência, carteiros, policiais etc.) os quais são financiados por

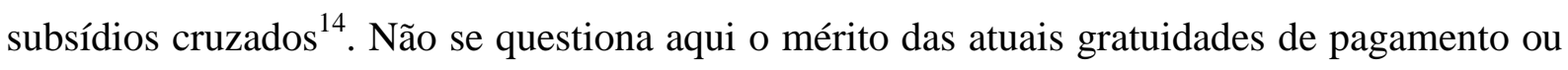
descontos na tarifa, nem tampouco a forma como é feita, mas se enaltece o fato de que a mobilidade das pessoas melhorou; os idosos e deficientes físicos que eram discriminados há um tempo atrás agora tem mobilidade e acesso a todos os recantos da cidade por meio da isenção de tarifas e o aparelhamento dos meios de transporte para receber aqueles passageiros.

A qualidade de vida e o desenvolvimento sustentável passaram a ser o grande objetivo das legislações de trânsito nacionais e das políticas de mobilidade urbana. O enfrentamento

\footnotetext{
${ }^{13}$ BRASIL, 2004, p. 19-46.

${ }^{14}$ Significa que são os demais usuários que financiam tais segmentos, o que muitas vezes provoca distorções: acontecem casos nos quais uma pessoa mais pobre (um desempregado, por exemplo), quando paga uma tarifa sem descontos, subsidia a tarifa de uma pessoa em melhores condições financeiras (um estudante de classe média, por exemplo)
} 
dos problemas da mobilidade urbana vinculados à questão urbana favoreceu o desenvolvimento dos argumentos da política em prol da sustentabilidade ambiental e socioeconômica das cidades.

Em agosto de 2007, o presidente da República encaminhou ao Congresso Nacional o projeto de lei (PL) que institui as diretrizes da política de mobilidade urbana e aprova outras providências (PL no 1.687/2007). Este projeto consubstancia a política de desenvolvimento urbano no que se refere aos transportes urbanos, regulamentando os artigos 21, inciso XX, e 182 da Constituição Federal. As diretrizes da política de mobilidade urbana foram formuladas pela Secretaria Nacional de Transporte e da Mobilidade Urbana do Ministério das Cidades, num processo de discussão que se iniciou em setembro de 2004 e foi concluído em agosto de 2006, quando da sua aprovação pelo Conselho das Cidades.

A essência do projeto de lei é a reforma regulatória dos serviços de transporte coletivo e a mudança institucional no ambiente da mobilidade urbana. O projeto tem como princípio a eqüidade social e como objetivo a sustentabilidade socioeconômica e ambiental das cidades brasileiras.

Os transportes urbanos, por sua vez, foram definidos "como o conjunto dos meios e serviços utilizados para o deslocamento de pessoas e bens na cidade" (art. $1^{\circ}$, parágrafo único, do PL 1.687/2007) ${ }^{15}$. A política de mobilidade urbana tem, deste modo, objeto mais amplo que os serviços de transportes urbanos: trata-se, na verdade, da relação dos deslocamentos de pessoas e bens com a própria cidade e de seu planejamento para o desenvolvimento de suas funções sociais, proporcionando o acesso universal dos cidadãos às oportunidades que a vida na cidade oferece.

\section{A mobilidade urbana e o meio-ambiente}

${ }^{15}$ Conforme a exposição de motivos interministerial do PL n ${ }^{\mathrm{o}} 1.687 / 2007$, o Estatuto da Cidade (Lei $\mathrm{n}^{\mathrm{o}} 10.257$, de julho de 2001) estabeleceu as diretrizes gerais e os instrumentos da política urbana, regulamentando os arts. 182 e 183 da Constituição. Entretanto, com relação à mobilidade urbana, o estatuto dispôs apenas sobre a obrigatoriedade da existência de plano de transporte urbano integrado para os municípios com mais de quinhentos mil habitantes (art. $41, \S 2^{\circ}$ ). O legislador optou tratar das questões relativas aos transportes urbanos tão-somente na sua interação direta com um dos instrumentos da política urbana, o plano diretor municipal, remetendo, dessa maneira, para outro título legal, a fixação das diretrizes para os transportes urbanos, assim como o fez em relação aos demais setores de desenvolvimento urbano, como o saneamento básico, por exemplo. Ademais, o conceito de mobilidade urbana adotado, por ser mais amplo que o de transportes urbanos, contém conhecimentos específicos, técnicos e jurídicos suficientemente desenvolvidos para justificar um título autônomo. 
O termo mobilidade implica o deslocamento entre dois pontos, a origem e o destino. Qualquer pessoa tem o poder e o direito de se deslocar e todas as possibilidades de deslocamentos na cidade é que compõem o cenário da mobilidade urbana. Neste contexto, encontram-se pedestres, ciclistas, usuários de transporte coletivo e motoristas. $\mathrm{O}$ desafio de tornar as cidades cada vez mais sustentáveis é um anseio que envolve o mundo todo.

A população urbana no Brasil já ultrapassou os $82 \%$ da população total, segundo dados do Ministério das Cidades. Pouco mais de 8\% dos municípios possuem mais de 55\% do total dos habitantes do país.

Mas, afinal, o que se entende por mobilidade urbana?

"Mobilidade urbana é o resultado da interação dos deslocamentos de pessoas e bens entre si e com a própria cidade. Isso significa que o conceito de mobilidade urbana vai além do deslocamento de veículos ou do conjunto de serviços implantados para estes deslocamentos. Pensar a mobilidade urbana é mais que tratar apenas transporte e trânsito."

Tomando-se por base o conceito do Ministério das Cidades transcrito acima, a mobilidade urbana envolve o uso e a ocupação do solo urbano, os sistemas de transporte, a infraestrutura dos caminhos e a interação entre fator humano, veículo, via pública e meio ambiente. Portanto, constata-se que todos esses elementos estão interligados, atuando de forma articulada, ou seja, um necessitando do outro para conviver em harmonia. Nesse sentido, a perspectiva sistêmica refere que "embora possamos discernir partes individuais em qualquer sistema, essas partes não são isoladas, e a natureza do todo é sempre diferente da mera soma de suas partes". ${ }^{17}$

A necessidade de mobilidade tem se alterado expressivamente nos últimos anos devido a dispersão urbanística residencial, descentralização das atividades e serviços, crescente transporte individual e ineficiência do transporte coletivo, trazendo como consequiência o ruído, a poluição atmosférica e o agravamento da sustentabilidade energética.

Ressalta-se que a interligação dos diversos modos de transporte é um fator muito importante para a qualidade do ambiente urbano, assim como a continuação das redes, a segurança, o conforto e a atratividade. Cumpre salientar que o pedestre tem função primordial

\footnotetext{
${ }^{16}$ BRASIL. Ministério das Cidades, 2006.

${ }^{17}$ CAPRA, 2001, p.41.
} 
no que se refere a mobilidade urbana, porquanto, ele exerce a função de autotransporte e, ao mesmo tempo, pode carregar pequenos objetos, assim como informações.

Algumas situações da realidade enfrentadas no cotidiano das pessoas passam a restringir ou dificultar a mobilidade urbana, tais como: a precariedade da infra-estrutura urbana, ausência de passeios, iluminação e equipamentos de drenagem; a apropriação ilegal do espaço público por ambulantes, bares ou comerciantes; a ausência de arborização urbana, perda da qualidade ambiental, e pouca atratividade para o pedestre; deficiência no planejamento urbano, aumento do tempo de deslocamento e do custo do transporte e segurança.

Ainda, muitos dos locais freqüentados pelos pedestres são inacessíveis para os portadores de necessidades especiais e isso também contribui, de forma negativa, para a restrição da participação destas pessoas nas atividades públicas urbanas. Essas condições de mobilidade afetam diretamente o desenvolvimento social e econômico das cidades, assim como, a qualidade do ambiente. Diante disso, percebe-se que as questões da mobilidade urbana estão inerentemente ligadas ao planejamento do meio físico e da organização das cidades, já que todos esses fatores influenciam diretamente a sustentabilidade.

Contudo, a atividade de transportar mercadorias e pessoas é naturalmente geradora de alguma forma de poluição sobre o ambiente em que ela está inserida, seja a poluição atmosférica referente aos resíduos emitidos na atmosfera, a poluição sonora referente aos ruídos gerados, e também a poluição visual referente à degradação da paisagem urbana.

No que se refere aos deslocamentos no Brasil, tem-se que $85 \%$ da população é motorizada e $15 \%$ é constituída por pessoas não motorizadas. Ainda, conforme dados da Pesquisa da Agência Nacional de Transportes sobre mobilidade da população urbana ${ }^{18}, 60 \%$ dos deslocamentos são realizados através de transporte coletivo e $40 \%$ são realizados individualmente.

Deste modo, o sistema de trânsito ocupa um papel de destaque sob o aspecto social e econômico, na medida em que envolve, no dia-a-dia, praticamente os cidadãos de todo o mundo, no exercício do seu direito de ir e vir, de se locomover livremente, para a satisfação

\footnotetext{
${ }^{18}$ NTU - Pesquisa de Mobilidade da População Urbana, 2006. p.11-12.
} 
de suas necessidades, em busca de seu bem estar e o da comunidade em que vive. Nesse sentido,

[...] materializam-se formas urbanas cada vez mais estendidas sobre vastas superfícies, criando novas relações cotidianas entre pessoas e lugares. É nesse contexto que se torna pertinente revisitar o conceito de "migração pendular", e a discussão atual que sugere uma outra denominação, qual seja a de "movimento pendular". [...] os deslocamentos para o trabalho assumem importância crescente, integrando o núcleo metropolitano, que é o centro da produção, às áreas do entorno residencial. [...] Neste texto, optou-se pelo uso dos termos "movimento" ou "deslocamento" pendular, por se entender que tal dinâmica envolve um deslocamento diário e que, portanto, não implica transferência para ou fixação definitiva em outro lugar. ${ }^{19}$ (p.122-123)

Os deslocamentos diários fazem parte da vida atual em sociedade. Contudo, as cidades estão sentido a necessidade de mudanças nos seus percursos a fim de contemplar a mobilidade da população de forma eficiente, respeitando principalmente, o ambiente em todas as suas expressões. A elaboração de Plano Diretor ganha extrema importância no que se refere a organização das vias e dos deslocamentos nas cidades.

Importa ressaltar que algumas cidades mais antigas foram se formando sem a elaboração de estradas, pois na época não se tinha idéia das facilidades para se comprar um automóvel, ao passo que, outras, foram desenhadas, principalmente, para o trânsito de automóveis. Hoje, a realidade conduz a um novo conceito para a qualidade de vida, pretendendo alternativas que não prejudiquem o ambiente e promovam a saúde dos cidadãos, mas que acima de tudo garantam o acesso seguro e confortável a todos.

Ainda nos dias atuais, as cidades metropolitanas se deparam com ocupações irregulares - favelas de alvenaria - que surgem em velocidade e extensão assustadoras, gerando mobilidade clandestina sem planejamento e sem controle. Aliás, o planejamento urbano é um processo praticamente inexistente. As propostas pretendidas nesses meios são sempre atrasadas confrontando-se com a realidade incontrolada que se implanta. ${ }^{20}$

A poluição é um dos grandes problemas enfrentados pelas cidades no que se refere a mobilidade urbana de veículos. O Estado de São Paulo detém $40 \%$ da frota motorizada do País (14,5 milhões de veículos - 7,5 milhões na RMSP), um veículo para cada dois habitantes.

19 MOURA, Rosa; BRANCO, Maria Luisa Gomes Castello; FIRKOWSKI, Olga Lúcia C. De Freitas. Movimento pendular e perspectivas de pesquisas em aglomerados urbanos. São Paulo em perspectiva, v. 19, n. 4, p. 121-133, out./dez. 2005

${ }^{20}$ SCARINGELLA, Roberto Salvador. A crise da mobilidade urbana em São Paulo. São Paulo em perspectiva, v.15, n.1, 2001. p.55. 
A fumaça dos veículos Diesel contribui com $40 \%$ das partículas inaláveis respiradas na RMSP. O transporte individual vem aumentando sua participação no total de viagens. Cerca de 55\% da frota circulante apresenta idade superior a 10 anos. Cerca de $40 \%$ da frota é originalmente equipada com tecnologias modernas (catalisador/injeção eletrônica). ${ }^{21}$

Importa salientar que, no Brasil, a opção pelos meios de transporte a serem utilizados ainda tem dependência direta com a posição sócio-econômica familiar. As individualidades também são fatores de ingerência na mobilidade bem como o consumismo e comodismo. A preferência pelo transporte individual ao coletivo ratifica a preferência da população àquele que socialmente possa lhe conferir um melhor status, bem ainda o descaso com as questões ambientais. Outro exemplo desse status vinculado às espécies de meios de transporte é a cada vez maior troca da frota dos veículos de passeio (carros menores) por utilitários, que são muito maiores, os demandam maior espaço nas vias e estacionamentos e que consomem mais combustível.

Os combustíveis contêm altos teores de enxofre, aromáticos, olefinas, etc. (gases de efeito estufa). Cerca de $70 \%$ dos veículos circulam desregulados e com deficiência na manutenção. No Brasil, os congestionamentos provocam redução média da produtividade dos trabalhadores; em 10 cidades brasileiras os custos sociais ultrapassam 500 milhões de reais por ano (IPEA/ANTP). Na RMSP, observa-se um aumento nas internações e mortes entre crianças e idosos (8\% FMUSP), devido aos níveis de concentração de partículas inaláveis. ${ }^{22}$

$\mathrm{O}$ aumento descontrolado dos carros em circulação faz com que as grandes metrópoles brasileiras estejam entre as cidades mais ruidosas do planeta. Em São Paulo, $10 \%$ dos veículos leves que circulam emitem ruído acima dos padrões aceitáveis por falta de manutenção adequada. Para os veículos pesados e motos, estima-se que o índice seja maior, e

\footnotetext{
${ }^{21}$ Secretaria de Estado do Meio Ambiente Companhia de Tecnologia de Saneamento Ambiental. PLANO DE CONTROLE DA POLUIÇÃO POR VEÍCULOS EM USO PCPV - PARA UM TRANSPORTE SUSTENTÁVEL NO ESTADO DE SÃO PAULO. Disponível em: http://homologa.ambiente.sp.gov.br/EA/adm/admarqs/Olimpio_de_Melo.pdf. Acesso em: 25/05/2009.

${ }^{22}$ Secretaria de Estado do Meio Ambiente Companhia de Tecnologia de Saneamento Ambiental. PLANO DE CONTROLE DA POLUIÇÃO POR VEÍCULOS EM USO PCPV - PARA UM TRANSPORTE SUSTENTÁVEL NO ESTADO DE SÃO PAULO. Disponível em: http://homologa.ambiente.sp.gov.br/EA/adm/admarqs/Olimpio_de_Melo.pdf. Acesso em: 25/05/2009.
} 
com isso, o aumento de estresse por poluição sonora além de problemas renais, cardíacos, perda da audição entre outros. ${ }^{23}$

Com o avanço das mudanças climáticas observadas ultimamente no planeta, reconhecidas recentemente por organismos ligados a ONU como conseqüência das ações do homem, os compromissos dos países com a redução da poluição são cada vez maiores, principalmente, com a redução da emissão de gases do efeito estufa - na qual o dióxido de carbono (CO2) se destaca - que estão fortemente ligados à atividade de transporte. Um dos grandes destaques atuais no que se refere a proteção do meio ambiente é o protocolo de Kyoto, assinado e ratificado pelo Brasil, o qual estabelece que os países signatários tenham um prazo até 2012 para reduzir as emissões de gases do efeito estufa em cerca de 5\% em relação ao total observado no ano de 1990.

Nessa lógica, de acordo com simulações da Associação Nacional das Empresas de Transportes Urbanos - NTU realizadas com base nos parâmetros de emissões do PROCONVE $^{24}$, pode-se afirmar que o usuário do automóvel emite 9 vezes e a motocicleta 17 vezes mais $\mathrm{CO} 2$ do que um ônibus urbano ${ }^{25}$, quando se considera a poluição por passageiro transportado.

Os Programas Estratégicos e as Ações da $\mathrm{SEMOB}^{26}$, integrados com as demais Políticas Urbanas, visam mudar radicalmente a atuação do Governo Federal, aliando-o aos Estados e Municípios para desenvolver e implementar uma Política Nacional de Mobilidade Urbana Sustentável, centrada no desenvolvimento sustentável das cidades e na priorização dos investimentos federais nos modos coletivos e nos meios não motorizados de transporte.

Ainda, a Política Nacional de Mobilidade Urbana adotada pelo Ministério das Cidades tem como objetivo da discussão das questões relacionadas à Mobilidade Urbana na cidade é para que as cidades adotem as seguintes medidas: enfatizar o uso do transporte coletivo e não do transporte individual; reduzir os congestionamentos na cidade; diminuir a poluição

\footnotetext{
${ }^{23}$ Secretaria de Estado do Meio Ambiente Companhia de Tecnologia de Saneamento Ambiental. PLANO DE CONTROLE DA POLUIÇÃO POR VEÍCULOS EM USO PCPV - PARA UM TRANSPORTE SUSTENTÁVEL NO ESTADO DE SÃO PAULO. Disponível em: http://homologa.ambiente.sp.gov.br/EA/adm/admarqs/Olimpio_de_Melo.pdf. Acesso em: 25/05/2009.

${ }^{24}$ Programa de Controle da Poluição do Ar por Veículos Automotores.

${ }^{25}$ Os cálculos de emissões por passageiro estão disponíveis no site da NTU - www.ntu.org.br - na seção Publicações/Anuário.

${ }^{26}$ Disponível em: http://www.cidades.gov.br/secretarias-nacionais/transporte-e-mobilidade.
} 
ambiental gerada pelos meios de transporte; diminuir o número de acidentes de trânsito; incentivar a utilização de combustíveis não poluentes e renováveis; orientar os investimentos públicos no setor de transportes; orientar os equipamentos, a distribuição de infra-estrutura de transportes, a circulação e distribuição de mercadorias e pessoas na cidade.

De acordo com a Política Nacional de Mobilidade Urbana Sustentável coordenada pelo Ministério das Cidades $^{27}$ devem ser observadas na elaboração de Planos Diretores municipais e da legislação urbanística, as seguintes diretrizes: diminuição do número de viagens motorizadas; revisão do desenho urbano; revisão da circulação de veículos; desenvolvimento de meios não motorizados de transporte; reconhecimento da importância do deslocamento dos pedestres; proporcionar mobilidade às pessoas com deficiência e restrição de mobilidade; priorização do transporte público coletivo; qualificação do espaço urbano; investimento em passeios (calçadas), em arborização urbana, equipamentos públicos com acessibilidade a todos os cidadãos, construção de espaços mais acessíveis (sem barreiras arquitetônicas), estruturação da gestão local.

Também, o Brasil conta com recomendações da Câmara Técnica para a discussão da regulamentação da Lei Federal $n^{\circ}$ 10.098/00 para adequação da legislação urbanística municipal a ser seguida por todos os municípios brasileiros que traz orientações importantes no que se refere a mobilidade urbana:

exigir a garantia da faixa mínima para circulação de pedestres livre de obstáculos,
rebaixamento de guias com faixa tátil, um traçado das vias que permita cruzamentos
mais seguros e a execução da calçada conforme as determinações do decreto n
$5.296 / 04$ e a NBR9050 na legislação de parcelamento do solo; garantir os $2 \%$ de
vagas nos estacionamentos para portadores de deficiência em função do
planejamento do uso do solo, na lei de zoneamento municipal; garantir a instalaçãa e
sinalização de mobiliário urbano adequado, disciplinar a propaganda e a instalação
de feiras e camelôs no Código de Posturas; nas leis sobre patrimônio histórico e
cultural deve prevalecer o máximo grau de acessibilidade com o mínimo da
alteração do imóvel; exigir a garantia de acesso da rua a toda edificação de uso
público ou coletivo, banheiro acessível, elevadores com medidas compatíveis, entre
outros, assegurando a adequação dos parâmetros técnicos estabelecidos no Decreto
$\mathrm{n}^{\circ} 5.296$ e na NBR9050, no Código de Obras; incluir estratégias que favorecem a
mobilidade urbana com prioridade ao pedestre, no Plano Diretor. ${ }^{28}$

Em se tratando de transportes, esse ponto pode ser trabalhado através da busca pela qualidade de vida com vista em práticas de mobilidade urbana sustentável. Nesse sentido, a

\footnotetext{
27 BRASIL. Ministério das Cidades, 2004, v. 6, p.63-66.

${ }^{28}$ Disponível em: http://www.planuts.com.br/Mobilidade\%20Urbana.htm. Acessado em: 04/06/2009.
} 
legislação brasileira já contribuindo de forma ativa, pois o país já conta Plano de controle da poluição por veículos em uso ${ }^{29}$, estabelecido pelas Resoluções do CONAMA números 18/95 e 256/99 e Resolução SMA São Paulo 31/2000 que, da mesma forma, contribuem para o cuidado do ambiente, assim como trazem alternativas para a melhora da mobilidade urbana. Ainda, o país já conta com o Programa de melhoria da qualidade dos combustíveis que envolve esse plano de ação da SEMOB. ${ }^{30}$ Também, no Estado de São Paulo já está implantando um plano de ação que visa a fiscalização de fumaça preta, onde a CETESB e a Polícia Rodoviária fiscalizam veículos à Diesel, conforme determina a legislação ambiental. ${ }^{31}$

A preocupação com o desenvolvimento sustentável tem incentivado o estudo e a implantação, em diferentes setores, de medidas e procedimentos que contribuam para a sustentabilidade em áreas urbana. Em relação aos transportes esta questão pode ser vista através de uma busca pela mobilidade urbana sustentável. Esta busca deve ter como base o conceito de desenvolvimento sustentável em que se procura de uma forma geral, definir estratégias dentro de uma visão conjunta das questões: sociais, econômicas e ambientais. $^{32}$ No que se refere a mobilidade urbana sustentável, a Agência Nacional de Transportes Públicos adota o seguinte conceito:

\begin{abstract}
mobilidade urbana sustentável é o resultado de um conjunto de políticas de transporte e circulação que visam proporcionar o acesso amplo e democrático ao espaço urbano, através da priorização dos modos de transporte coletivo e não motorizados de maneira efetiva, socialmente inclusiva e ecologicamente sustentável. ${ }^{33}$
\end{abstract}

\footnotetext{
29 A Resolução n. ${ }^{\text {1 }}$ 18/86 do CONAMA teve como plano de ação a implantação do PROCONVE. Esse procedimento tem tido grandes resultados no Estado de São Paulo: veículos leves novos apresentam uma redução de $90 \%$ na emissão dos poluentes. Veículos pesados novos apresentam uma redução significativa na emissão dos poluentes e atendem aos padrões de emissão da legislação. VER FONTE!!!

${ }^{30}$ Ainda, o Programa de melhoria da qualidade dos combustíveis tem obtido os seguintes resultados: Álcool garantia da adição de $22 \%$ à gasolina para o melhor controle ambiental (o uso do álcool é uma medida que favorece a redução do efeito estufa). Diesel - melhoria na redução do teor de enxofre de $0,7 \%$ para $0,2 \%$ na Região Metropolitana de São Paulo e para 0,5\% nas demais regiões do Estado. Disponível em: Secretaria de Estado do Meio Ambiente Companhia de Tecnologia de Saneamento Ambiental. PLANO DE CONTROLE DA POLUIÇÃO POR VEÍCULOS EM USO PCPV - PARA UM TRANSPORTE SUSTENTÁVEL NO ESTADO DE SÃO PAULO. Disponível em: http://homologa.ambiente.sp.gov.br/EA/adm/admarqs/Olimpio_de_Melo.pdf. Acesso em: 25/05/2009.

${ }^{31}$ Disponível em: Secretaria de Estado do Meio Ambiente Companhia de Tecnologia de Saneamento Ambiental. PLANO DE CONTROLE DA POLUIÇÃO POR VEÍCULOS EM USO PCPV - PARA UM TRANSPORTE SUSTENTÁVEL NO ESTADO DE SÃO PAULO. Disponível em: http://homologa.ambiente.sp.gov.br/EA/adm/admarqs/Olimpio_de_Melo.pdf. Acesso em: 25/05/2009.

${ }^{32}$ CAMPOS, Vânia Barcellos Gouvêa. Uma visão da mobilidade urbana sustentável.

${ }^{33}$ BRASIL. ANTP, 2003.
} 
A necessidade do cuidado ambiental e da promoção da mobilidade urbana vem no sentido de atender os propósitos pretendidos no art. 225, da Constituição Federal, assim como no Relatório Brundtland da ONU que projetam a idéia de desenvolvimento sustentável de forma a atender as necessidades atuais e futuras, ou seja, das gerações presentes e futuras. Nesse sentido, o desenvolvimento deve ser entendido como crescimento. Assim, desenvolvimento sustentável é o crescimento de maneira proporcional sem prejuízo dos valores humanos, portanto,

mobilidade sustentável é a capacidade de dar resposta às necessidades da sociedade em deslocar-se livremente, aceder, comunicar, negociar e estabelecer relações, sem sacrificar outros valores humanos e ecológicos hoje ou no futuro. ${ }^{34}$

O pedestre é o membro primordial da mobilidade urbana sustentável, mas para que ele continue efetivo no meio, é muito importante que a acessibilidade seja eficaz em todos os locais. As políticas publicas que tratem de preservação ambiental e mobilidade devem ser implementadas para que a acessibilidade de pessoas com necessidades especiais e de idosos não deixem de ser respeitada. A organização urbana e o controle do crescimento imobiliário devem ser rígidos para que o ambiente seja protegido e para que se faça valer o conceito de desenvolvimento sustentável, de uma forma geral, nas questões sociais, econômicas e ambientais.

\section{Políticas públicas: alternativas de preservação ambiental e mobilidade}

Um dos principais direitos que o cidadão possui perante a sociedade é o direito da circulação, mas para que este seja exercido, é necessário o respeito a alguns princípios, independência, autonomia e dignidade, tanto no coletivo como no individual.

O crescimento do uso do automóvel e o decréscimo dos outros meios de transportes (público, bicicleta e a pé) causaram efeitos preocupantes na organização das cidades.

É importante a criação de planos de ações que visem garantir o equilíbrio do sistema, promovendo o desenvolvimento em contrapartida a preservação do ambiente. Há necessidade de atrair atenção das autoridades para situações enfrentadas pela população no dia-a-dia. Assim,

\footnotetext{
${ }^{34}$ World Business Council for Sustainable Development.
} 
para que um problema chame a atenção do governo e da classe política, rompendo com a situação de "equilíbrio" e "realimentação negativa", é necessária a construção de um novo entendimento sobre o mesmo ou de uma nova imagem. ${ }^{35}$

$\mathrm{O}$ direito à circulação está previsto no art. $2^{\circ}, \mathrm{I}$ e V, do Estatuto das Cidades. Assim, a função circular demonstra a necessidade de transporte ao passo que propõe a garantia do direito a cidades sustentáveis. É nesse sentido que surgem as políticas públicas com objetivos preventivos e repressivos no cuidado ambiental. A simples constatação dos problemas advindos da mobilidade urbana não garante a instauração de políticas públicas. Assim sendo,

o reconhecimento de um problema, por si só, não garante a ação do governo por meio de uma política pública: é necessário um contexto favorável. A junção entre problema, solução e decisão para o encaminhamento de uma política seguem, assim, uma lógica sistêmica e contingente. ${ }^{36}$

Essa lógica sistêmica demonstra que o sistema de trânsito não depende apenas do poder público, o contexto favorável será dado pelo clamor da população por organização, mas o desempenho do trânsito depende também da atuação do condutor e do pedestre. Mas, sobretudo, o investimento em um transporte público de qualidade ${ }^{37}$ seria a melhor maneira de reduzir o transporte individual promovendo ainda uma redução efetiva na poluição das grandes cidades brasileiras.

O país já tem pensado em alternativas para a fiscalização de veículos com IPVA atrasado, multas e outros a fim de possibilitar a mobilidade urbana de forma eficiente, retirando das rodovias veículos defasados e sem as mínimas condições de tráfego:

a identificação eletrônica do veículo - que deve ser entendido como parte do trânsito inteligente - é fator essencial na solução do pedágio urbano e já constitui realidade em algumas rodovias. O sistema é útil para todo o monitoramento do trânsito e beneficia inclusive a segurança pública. ${ }^{38}$

Certamente que ainda é pouco frente ao problema de mobilidade, mas que ameniza o tráfego e gera maior segurança aos transeuntes.

\footnotetext{
${ }^{35}$ GOMIDE, Alexandre de Ávila. Agenda governamental e o processo de políticas públicas: o projeto de lei de diretrizes da política nacional de mobilidade urbana. Texto para Discussão: IPEA, Brasília , n. 1334 , p. 1-24, 2008. p.12.

${ }^{36}$ GOMIDE, Alexandre de Ávila. Agenda governamental e o processo de políticas públicas: o projeto de lei de diretrizes da política nacional de mobilidade urbana. Texto para Discussão: IPEA, Brasília, n. 1334 , p. 1-24, 2008. p.12.

${ }^{37}$ Anuário 2008/2009.p.50.

${ }^{38}$ SCARINGELLA, Roberto Salvador. A crise da mobilidade urbana em São Paulo. São Paulo em perspectiva, v.15, n.1, 2001. p.59
} 
A implementação de tecnologias de controle propiciam a fiscalização intensiva do tráfego e da mobilidade, já que o número de policiais para suprir as tarefas de fiscalização tem se demonstrado insuficientes em razão da grande demanda de veículos em circulação nas rodovias do país.

Importa referir que a qualidade do ambiente também está ligada à situação da infraestrutura física, ou seja, devem-se cumprir as exigências da NBR $9050^{39}$ nos espaços destinados aos pedestres, dentre elas, a existência de piso tátil direcional e de alerta, materiais adequados, iluminação, arborização, rebaixamento de calçadas com rampa acessível ou elevação das vias para travessia de pedestre em nível e adaptação e revitalização das calçadas existentes. A canalização não deve interferir nos passeios, sendo localizada sob a calçada, o percurso do estacionamento até as entradas principais deve ter uma rota acessível, além da sinalização indicativa, informativa e direcional em todos os espaços.

A Agenda 21 é outro plano de ação importante na preservação do meio ambiente, já que envolve 179 países na tentativa de promover um novo padrão de desenvolvimento, com vista na proteção ambiental, sustentabilidade urbana, justiça social e eficiência econômica. Este plano pode ser adotado global, nacional ou localmente, em qualquer área de impacto ambiental pela ação do homem. Outros acordos importantes para o meio ambiente são: a Convenção das Nações Unidas sobre o Direito do Mar, a Convenção de Viena para Proteção da Camada de Ozônio e o Protocolo de Kyoto.

Cumpre salientar que as questões de gênero também envolvem a não utilização de alguns meios de transporte e, por isso, requerem planos de ação efetivos para inclusão na mobilidade urbana. Os trens e metros tem sido alvo de discussão em razão dos abusos sofridos pelas mulheres ao utilizarem o veículo nos períodos de pico. O Rio de Janeiro já tentou solucionar a problemática através da criação da Lei Estadual 4.733/2006 ${ }^{40}$, que

\footnotetext{
39 Acessibilidade é a possibilidade e condição de alcance, percepção e entendimento para a utilização com segurança e autonomia de edificações, espaço, mobiliário, equipamento urbano e elementos. Para os transportes isto significa facilidade em distâncias, tempo, custos e autonomia.

${ }^{40}$ O Órgão Especial do Tribunal de Justiça do Rio de Janeiro entendeu que a Lei Estadual 4.733/2006, que criou os vagões exclusivos para mulheres nos horários de pico nos trens e no metrô, é constitucional. A decisão foi em uma arguição de inconstitucionalidade, suscitada pela $13^{\text {a }}$ Câmara Cível do TJ fluminense ao ao analisar recurso do Ministério Público contra decisão de primeira instância que havia extinguido Ação Civil Pública do MP sem exame do mérito. Em Ação Coletiva, o Ministério Público argumentou que a aplicação da lei, sob o pretexto de evitar casos de assédio sexual, teria ferido o direito à igualdade e de escolha de homens e mulheres. A ação foi movida contra as empresas SuperVia e a Opportrans, que administram o sistema ferroviário e metroviário do
} 
designou vagões exclusivos para mulheres nos horários de pico nos trens e no metrô. Talvez ainda se precise refletir acerca da solução encontrada, mas já se trata de um grande avanço no incentivo do transporte coletivo.

A crescente preocupação da população, bem como das autoridades no que se refere a proteção do meio ambiente tem trazido soluções ecologicamente corretas, entre elas, podemos destacar os carros elétricos e híbridos; a utilização de combustíveis menos poluentes: gás natural, o biodisel ${ }^{41}$, o biocombustível de algas ${ }^{42}$, o biocombustível de $\operatorname{soja}^{43}$ e o óleo vegetal $^{44}$.

Cumpre ressaltar que, embora as novas tecnologias, voltadas para a preservação ambiental, tenham grandes méritos para ingressar no mercado, elas acabam por sofrer boicotes das indústrias que terão perdas caso a nova tecnologia ganhe adeptos:

é o que acontece [...] com o carro elétrico, que está desenvolvido, mas não é comercializado, pois sofre os efeitos daquilo que se costuma chamar de dependência da trajetória. A trajetória das cadeias produtivas e de serviços para carros a combustível, redes de companhias, postos de gasolina, álcool e diesel, distribuidoras de petróleo, etc.; ou seja, o mercado se mostra dificilmente substituível. ${ }^{45}$

estado. As concessionárias foram acusadas pelo MP de criar privilégios ao obedecerem à lei. Os desembargadores do Órgão Especial concluíram que a norma foi apenas mais um esforço para se proteger um direito da mulher. O relator do processo, desembargador Valmir de Oliveira Silva, citou parecer da própria Procuradoria-Geral de Justiça, que em processo administrativo interno opinou pela constitucionalidade da medida. Na ação, o promotor Rodrigo Terra afirma que, além de não garantir a inocorrência do assédio, a lei pode causar outra espécie de dano. "A mulher que não faça questão do tratamento privilegiado terá de conviver com a possibilidade de que a julguem 'prostituta', enquanto o homem que esteja no vagão especial será visto como um 'pervertido'". O processo foi encaminhado para o Órgão Especial do TJ afim de apreciar o incidente de inconstitucionalidade, que ocorreu na última segunda-feira (20/7). Em seu voto, o desembargador Valmir de Oliveira Silva classificou a argumentação do promotor de exagerada. Disponível em: http://www.conjur.com.br/2009-jul-23/lei-criou-vagoes-mulheres-rio-constitucional. Acesso em: 24/07/2009.

http://www.youtube.com/watch?v=6KPdnhxWE7E\&feature=PlayList\&p=0D06A7D0C4FE3DA3\&index=0. Ver:

${ }_{42}$ Diferentemente de outras oleaginosas, as microalgas se reproduzem de forma exponencial. Mantidas em tanques rasos, elas conseguem se duplicar em qualquer tipo de água, da salgada à salobra. Seu principal alimento é o dióxido de carbono (CO2), o que lhes confere um segundo papel de "comedoras" de gases que afetam o ambiente. As microalgas encontradas no litoral brasileiro têm potencial energético para produzir 90 mil quilos de óleo por hectare. Disponível em: http://www.biodieselbr.com/noticias/biodiesel/alga-entra-menubiocombustiveis-22-01-09.htm. Acesso em: 27/05/2009.

${ }^{43}$ Principal base do biodiesel no Brasil, rende de 400 a 600 quilos de óleo por hectare e tem apenas um ciclo por ano. Disponível em: http://www.inovacaotecnologica.com.br/noticias/noticia.php?artigo=biodiesel-de\%20algasmarinhas\&id=. Acesso em: 25/05/2009.

${ }^{44}$ Ver: http://www.youtube.com/watch?v=r41WLb3insU.

45 DAL POZ, Maria Ester; BARBOZA, Denis Borges. Incertezas e riscos no patenteamento de biotecnologias: a situação brasileira corrente. p.93-138. In: IACOMINI, Vanessa. Propriedade intelectual e biotecnologia. Curitiba: Juruá, 2008. p.98-99 
Também, já se tem notícia da confecção do protótipo do primeiro veiculo igual a um de formula 1, mas produzido com matérias sustentáveis e renováveis. O carro é chamado de WorldFirst (Mundo em Primeiro lugar) e capaz de atingir um velocidade de $200 \mathrm{Km} / \mathrm{h}$ na curva. O chassi deste veículo foi produzido com amido de batata, utiliza bicombustível produzido também com sobras de chocolate e óleo vegetal e tem um toque especial que é o volante feito de cenouras e outros vegetais. Certamente este veiculo não pode entrar em uma competição de formula 3, porque o protótipo utiliza bicombustível e a categoria não permite, mas é o único detalhe que não permite o veiculo entrar na competição. Esse veículo diminui as emissões de poluentes, utiliza lubrificantes de óleo vegetais e um avançado catalisador. O objetivo do projeto é estar viabilizando o uso de tecnologias ambientalmente sustentáveis para os carros de corrida.

A bicicleta é o único veículo acessível a todas as classes, porém é junto às camadas de baixa renda que encontra sua maior utilidade. $\mathrm{O}$ ato de pedalar não acarreta praticamente nenhum prejuízo ao meio ambiente. Em relação à caminhada, a bicicleta multiplica por 4 a velocidade e reduz para 1/5 a energia necessária. Além de não usar combustível, a bicicleta é mais eficiente energeticamente que todos os demais veículos.

Possui alta flexibilidade, especialmente em situações de congestionamento de tráfego.

A bicicleta é, ao mesmo tempo, um meio de transporte e um instrumento de lazer. Contribui para a melhoria da saúde dos usuários. Requer padrões modestos de infra-estrutura para circular e estacionar. $^{46}$

Assim sendo, percebe-se a grande importância de promoção das políticas públicas no sentido de tentar encontrar soluções para a questão da mobilidade urbana de forma a propiciar alternativas de preservação ambiental.

\section{Conclusão}

$\mathrm{O}$ termo mobilidade refere-se às condições de acesso aos locais aos quais as pessoas precisam dirigir-se a fim de satisfazer as suas inúmeras necessidades. Como a maioria

\footnotetext{
$46 \quad$ Ver: http://www.cidades.gov.br/secretarias-nacionais/transporte-emobilidade/arquivos/Livro\%20Bicicleta\%20Brasil.pdf
} 
absoluta da população concentra-se nas áreas urbanas dos municípios, é nas cidades que aparece a maior parte dos problemas de mobilidade.

Atender às suas necessidades, para o que é necessário o deslocamento das pessoas no espaço e no tempo, é um direito de todos os cidadãos e, por isso, é dever do Estado criar as condições necessárias à mobilidade de todos.

A mobilidade urbana é proporcionada, exemplificativamente, pela rede viária, pelo sistema de transporte, pelas calçadas, de acordo com a forma como a cidade se organiza e as características das necessidades da população de cada local da cidade.

A coordenação dos diversos interesses, baseados nas diferentes capacidades de mobilidade das diferentes pessoas e nos diferentes locais, dá-se através da gestão da mobilidade urbana, cuja Política Nacional de Mobilidade Urbana do Ministério das Cidades constitui-se em um dos principais marcos de gestão da atualidade no que tange ao tema.

Como visto, o crescimento desordenado das cidades fomentado pela grave crise econômica é fator de agravamento de diversos problemas sociais urbanos, especialmente para os setores de baixa renda, com grandes impactos negativos ao meio ambiente e qualidade de vida. Dentre eles podem ser facilmente verificados degradação da qualidade de vida, redução da mobilidade das pessoas, aumento de congestionamentos, poluição atmosférica, acidentes de trânsito e a apropriação do espaço coletivo pelo automóvel.

A deficiência da mobilidade urbana e de acesso aos serviços de transporte coletivo, na medida em que excluem significativa parcela da população do acesso aos serviços essenciais e às oportunidades que as cidades oferecem, contribuem para a perpetuação da pobreza urbana e da exclusão social.

Nesse sentido, as políticas públicas de promoção da mobilidade urbana têm como um dos seus principais objetivos ampliar oportunidades e capacidades de superar a condição em que vivem através da melhoria da mobilidade e acessibilidade urbana. Isto é, com a melhoria das condições de acesso e deslocamento também se busca melhorar as oportunidades à população de melhorar suas próprias condições de vida, sejam de trabalho, de lazer, de saúde e assim por diante.

As reflexões postas no presente trabalho têm como principal objetivo analisar criticamente as condições de mobilidade atuais e contribuir para a formulação de políticas 
públicas nessa área que sejam integradas nos aspectos urbanos e sociais, já que os problemas, como visto, não são e não serão resolvidos por políticas setoriais, como, por exemplo, apenas a melhoria do sistema de transporte público.

Nesse sentido, permite-se concluir que a mobilidade deriva das necessidades de trabalho, saúde, estudo, lazer, o que implica na necessidade de que as ações voltadas à ampliação da mobilidade sejam aliadas a ações político-sociais para geração de empregos, ampliação da rede de saúde e áreas de lazer, extensão de estradas e de redes de saneamento básico. Qualquer ação, seja social, seja de mobilidade, implementada de forma dissociada da outra será falha e limitada, não alcançando a plenitude dos resultados esperados.

Certamente que tais desafios exigem também atuação política, para o que a participação popular é essencial, seja na adoção de novas medidas mais ambientalmente conscientes e responsáveis, seja na definição de prioridades e da forma de uso e ocupação dos espaços urbanos.

Há que se reconhecer os benefícios à melhoria da mobilidade urbana trazidos especialmente pela Política Nacional apresentada, ao menos no plano teórico. A eficácia de tal política, no entanto, somente poderá ser sentida pela polução se as diretrizes lá estabelecidas forem seguidas e implementadas pelos governos especialmente os locais, com a participação ativa e efetiva da população.

Espera-se, finalmente, que as anotações aqui tecidas contribuam para esclarecer melhor o tema e fomentar a participação popular de tal forma que este passe a ser tratado com a merecida importância pelos responsáveis pela execução de ações de promoção da mobilidade, bem como que tais ações tragam, realmente, sensíveis benefícios à população. $\mathrm{E}$ para isso, frise-se derradeiramente, importante que todos os cidadãos assumam seu papel de atores importantes e ativos na colaboração para a construção das ações necessárias, começando pela mudança de suas próprias atitudes e abandonando a posição de passividade que atinge grande parte dos brasileiros.

\section{Referências bibliográficas}

ASSOCIAÇÃO BRASILEIRA DE NORMAS TÉCNICAS. NBR 9050. Acessibilidade a Edificações, Mobiliário, Espaços e Equipamentos Urbanos. Rio de Janeiro - RJ, 2004. 
ASSOCIAÇÃO NACIONAL DAS EMPRESAS DE TRANSPORTES URBANOS. Pesquisa Mobilidade da População Urbana. Brasília: 2006. Disponível em: http://www.ntu.org.br/. Acesso em: 22/07/2009.

ASSOCIAÇÃO NACIONAL DAS EMPRESAS DE TRANSPORTES URBANOS. 100 anos do transporte urbano no Brasil. 1. ed. Brasília: 1997. Disponível em: http://www.ntu.org.br/. Acesso em: 22/07/2009.

BRASIL. Ministério das Cidades. Trânsito, questão de cidadania. Cadernos MCidades. Trânsito, n. 7, 2004.

BRASIL. Ministério das Cidades. Política nacional de mobilidade urbana sustentável. Cadernos MCidades. Mobilidade Urbana, n.6, 2004.

BRASIL. Ministério dos Transportes. Plano Nacional de Logística e Transportes. Disponivel em: www.transportes.gov.br. Acesso em: 24/07/2009.

CADAVAL, Maurício Eduardo Guimarães; GOMIDE, Alexandre de Ávila (orgs). Mobilidade urbana em regiões metropolitanas. In: Livro verde: Campinas: UNICAMP. IE, 2002.

CAMPOS, Vânia Barcellos Gouvêa. Uma visão da mobilidade urbana sustentável. Revista dos Transportes Públicos: ANTP, 2006 Disponível em: www.viverbemnacidade.org.br. Acesso em: 23/07/2009.

CAPRA, Fritjof. A teia da vida: uma nova compreensão científica dos sistemas vivos. 6.ed. São Paulo: Cultrix, 2001.

CONSELHO EMPRESARIAL PARA O DESENVOLVIMENTO SUSTENTÁVEL PORTUGAL. Mobilidade urbana sustentável: o impacto das empresas e dos seus trabalhadores. Disponível em: www.bcsdportugal.org. Acesso em: 22/07/2009.

DAL POZ, Maria Ester; BARBOZA, Denis Borges. Incertezas e riscos no patenteamento de biotecnologias: a situação brasileira corrente. p.93-138. In: IACOMINI, Vanessa. Propriedade intelectual e biotecnologia. Curitiba: Juruá, 2008.

GOMES, Daniela Vasconcellos. Solidariedade social e cidadania na efetivação do direito a um meio ambiente ecologicamente equilibrado. p.205-216. In: Revista Trabalho e Ambiente. Caxias do Sul, RS: Educs. v.4, n.7,jul./dez. 2006. 
GOMIDE, Alexandre de Ávila (coord.) Regulação e organização do transporte público urbano em cidades brasileiras: estudos de casos. Brasília: IPEA: Ministério das Cidades, 2004.

GOMIDE, Alexandre de Ávila. Agenda governamental e o processo de políticas públicas: o projeto de lei de diretrizes da política naiconal de mobilidade urbana. Texto para Discussão: IPEA, Brasília , n. 1334 , p. 1-24, 2008.

MILES, Duilio Castro. Planejamento e aprendizagem na implementação de políticas públicas: o caso da elaboração do planejamento de mobilidade urbana no município de São Leopoldo - (RS/Brasil). 2006. 366 f. Dissertação (Mestrado) - Universidade do Vale do Rio dos Sinos, Programa de Pós-Graduação em Administração

MINISTÉRIO DAS CIDADES. Política Nacional de Mobilidade Urbana Sustentável. Brasília: 2004. Disponível em: http://www.cidades.gov.br. Acesso em: 20/09/2008.

MINISTÉRIO DAS CIDADES. Trânsito, Questão e Cidadania. Caderno 7. Brasília: 2004.

PRIEUR, Michel. L' Environnement urbain. In: Droit de l'environnement. 5.ed. Paris: Dalloz, 2004. p.747-791.

SPAREMBEGER, Raquel Fabiana Lopes; MARTINS, Ezequiel. Urbanização, Estatuto da Cidade e meio ambiente. p.23-54. In: Revista Trabalho e Ambiente. Caxias do Sul, RS: Educs. v.3, n.4,jan./jun. 2005.

SEDU. Secretaria Especial de Desenvolvimento Urbano da Presidência da República/Grupo Executivo de Transporte Urbano. Política Nacional para o Transporte Urbano. Brasília, 72 p., mai. 2002.

SEMOB. Secretaria Nacional de transporte e da Mobilidade Urbana do Ministério das Cidades. Proposta de barateamento das tarifas do transporte público urbano. Brasília, $2006 . \quad$ Disponível em: www.cidades.gov.br/media/RelatorioBarateamentodasTarifasREVISADO.pdf. Acesso em: $15 / 06 / 2009$.

VASCONCELLOS, Eduardo A. Transporte urbanos nos países em desenvolvimento: reflexões e propostas. São Paulo: AnnaBlume. 4.ed, 2000. Disponível em: http://books.google.com.br/books?hl=pt-BR\&lr=\&id=rkb-

RA72qD8C\&oi=fnd\&pg=PA89\&dq=mobilidade, + transporte+urbano+e+meio+ambiente\&ots =guckqMn-Zn\&sig=vwhQSGrHUQT-dRHFTJ6-BFYa6cA. Acesso em: 22/07/2009.

XAVIER, José Carlos. Mobilidade urbana e desenvolvimento. In: Desafios do Desenvolvimento, Brasília, v. 2, n.07, fev. 2005, p.45. 